\title{
MOVIMENTOS SOCIAIS CONTEMPORÂNEOS E A DEMOCRACIA PARA ALÉM DO ESTADO: HIPÓTESES PARA O DEBATE
}

\author{
Cassio Brancaleone ${ }^{1}$ \\ Rodrigo Chaves de Mello
}

\begin{abstract}
Resumo: Ao longo das últimas décadas, os Estados de intenção democrática vem experimentando um desafio de grande magnitude que tem, nas bandeiras levantadas por um novo conjunto de movimentos sociais, o seu mais notável sintoma: em especial, a crise do estatuto da representação política. Esta crise estaria a afetar, de modo radical, os nexos de vinculação entre as instituições do Estado e o restante da vida social, e, no limite, poderia condenar a validade do desenho que atualmente dá cores e contornos aos dispositivos de inspiração democrática das poliarquias contemporâneas. Nesse artigo apresentamos duas hipóteses para pensar a crise da representação diante das interfaces entre movimentos sociais e democracia. Além do mais, ancorando nossas reflexões no atual circuito da indignação global, nos propomos a identificar os significados e desdobramentos de um duplo problema: de um lado, as condições de possibilidade de constituição de um horizonte democrático erigido para além das fronteiras normativas e institucionais da forma-Estado e da forma-Capital, de outro, o sentido de alguns entraves epistemológicos que operam com o poder de mantra na imaginação sociológica e política moderna, prisioneira do estadocentrismo enquanto princípio ontológico de construção da ordem social.
\end{abstract}

Palavras-chave: Representação. Estado. Democracia. Movimentos Sociais.

\section{INTRODUÇÃO}

Ao longo das últimas décadas, os Estados de intenção democrática vem experimentando um desafio de grande magnitude que tem, nas bandeiras levantadas por um novo conjunto de movimentos sociais, o seu mais notável

1 Doutor em Sociologia pelo IESP/UERJ, docente do PPGICH da UFFS, pesquisador do GPASE e membro do Grupo de Trabalho Anticapitalismos e Sociabilidades Emergentes do Conselho Latinoamericano de Ciências Sociais.

2 Doutor em Ciências Sociais pela UFJF, docente da UEVA, pesquisador do GPASE e membro do Grupo de Trabalho Anticapitalismos e Sociabilidades Emergentes do Conselho Latinoamericano de Ciências Sociais. 
sintoma. Do levante zapatista, em fins do século XX ao “ique se vayan todos!" argentino, em 2001, dos manifestantes egípcios na Praça Tahrir aos indignados espanhóis na puerta del Sol, da ocupação de Wall Street à tomada das ruas brasileiras, em junho de 2013, algo de novo e relevante desponta no cotidiano político e social. Em que pesem as diferenças próprias aos contextos de cada um destes movimentos, nos é patente a identificação de um horizonte comum ao qual apontam e a partir do qual se motivam. Isso porque, todos poderiam assinalar a profundidade da crise do estatuto da representação política, crise esta que estaria a afetar, de modo radical, os nexos de vinculação entre as instituições do Estado e o restante da vida social, e que, no limite, condenariam a validade do desenho que atualmente dá cores e contornos aos dispositivos de inspiração democrática dos Estados contemporâneos.

Desta forma, entendemos que na esteira de suas ações, estes movimentos sociais, ao reivindicarem (mais) democracia, trazem à baila elementos que apontam para rupturas práticas e discursivas com a gramática de normatização das poliarquias contemporâneas enquanto democracias de baixa intensidade, em especial, os limites estabelecidos pela arquitetura institucional do chamado Estado Democrático de Direito, constructo constitucional tributário do imaginário da Revolução Francesa. Diante deste dado, cabe-nos questionar: mas afinal, o que significa pensar a democracia para além do Estado? Quais horizontes e direitos estes movimentos vislumbram ao dissociarem democracia e Estado? Quais os conteúdos da palavra de ordem “Democracia real ya!”?

Diante de uma imagem esboçada por Marcel Gauchet (2009), de uma suposta batalha da democracia contra ela mesma, os atuais desafios que se impõem ao contexto político contemporâneo trazem-nos questões de tal monta que nos obrigam, entre outras coisas, a problematizar o quadro de nossa imaginação política e sociológica a partir da reconfiguração dos quadros normativos e repertórios de ação coletiva dos movimentos sociais da sociedade global.

Nesse sentido, gostaríamos de demarcar que, em nossa percepção, o tema da luta da democracia contra si mesma não deveria parecer uma excrescência histórica ou um oximoro de menor valor. A leitura que defenderemos ao longo deste trabalho, seguindo as pistas de Castoriadis (1987), é a de que a democracia pode (e deveria) ser concebida como um constante movimento de alargamento de si sobre si mesma. Com efeito, ao operarmos sobre o tema da "crise da representação política", consideramos que mais do que uma derrocada do cânone democrático, os impasses atualmente postos à democracia realmente 
existente (ou poliarquia, para simplificar com um toque de realismo liberal) estariam a nos demonstrar um sinal de sua vitalidade, manifestado na busca por ampliação das arenas e esferas de participação política (SOUSA SANTOS, 2002).

Nesta esteira, as ponderações tecidas por de Jacques Rancière (2014) em $O$ ódio à democracia, nos soam interessantes. Em sua abordagem, pensada enquanto reino do excesso, a democracia moderna se instauraria sob o signo de um paradoxo, prometendo ampliar, a um só tempo, tanto a participação popular na condução dos temas públicos quanto os modos e meios de satisfação da vida individual. No cerne deste paradoxo, indica-nos Rancière, o "Estado Democrático", em operação semelhante aos experimentos dos regimes totalitários, incitaria a promoção de um modelo de democracia socialmente homogeneizante, realizando para este fim a constante privatização do espaço público e a ininterrupta domesticação das fontes populares do poder político.

Como resultado dessa incessante disputa entre Estado e a autonomia do "poder do povo", encontramos em Rancière a crítica à democracia representativa como uma forma ineficaz de representação popular, tanto pela tendência do recorte oligárquico dos representantes em falsificarem os anseios e desejos da grande massa popular, quanto também pela minimização dos mecanismos de controle social efetivo sobre a ação dos mandatários ${ }^{3}$. Diante deste confisco da democracia pelas oligarquias políticas, aponta-nos Rancière, nos encontramos com a restrição do horizonte de definição da democracia quase que exclusivamente a seus momentos eleitorais ${ }^{4}$.

Assim, operada e legitimada através da chave da representação política, seria nesta redução da democracia (entendida enquanto poder popular, ou potência instituinte) em nome da democracia (entendida enquanto mercado eleitoral e jogo entre instituições do Estado, ou poder instituído) que encontraríamos uma das raízes de uma série de questões e problemas que, no curso dos dias atuais, as sociedades contemporâneas parecem querer nos devolver quando, através de seus movimentos sociais, clamam por mais democracia.

Embora inquietantes, não podemos perder de vista que as críticas de

3 Longe de ser novo, o tema da oligarquização da democracia possui ampla tradição no campo do pensamento político, consolidando um marco teórico próprio erguido em torno da chamada teoria das elites. Para os propósitos deste trabalho, destacaríamos, do interior desta tradição, a atualidade da obra de Robert Michels, A Sociologia dos Partidos Políticos (MICHELS, 1982).

4 É curioso o fato de que a provocação de Rancière possa ser ilustrada por uma tradicional campanha do Tribunal Superior Eleitoral do Brasil que diz em seu mote: “Seja Cidadão, vote!”. 
Rancière não são novas, e muito de suas preocupações não vão muito além de uma atualização de dilemas já apontados pela crítica anarquista há pelo menos 150 anos, como veremos a seguir.

Com efeito, se podemos tomar as problematizações teóricas apresentadas e os movimentos sociais contemporâneos como sintomas de questões que os ultrapassam, o presente trabalho promoverá uma reflexão sobre o significado da crise da representação política, entendendo que esta não seria apenas uma crise circunscrita aos modelos institucionais tradicionalmente à disposição das sociedades que se almejam democráticas, mas uma crise de dimensões mais profundas da representação tanto como imaginário dominante de uma esfera política autonomizada da vida social, quanto prática social e epifenômeno da vida política estatal, tal como forjados na modernidade. Para tanto, mobilizaremos, ao longo do texto, duas hipóteses interpretativas que indicariam, na esteira da ação dos movimentos, 1) o questionamento acerca da cumplicidade ontológica entre Democracia e Estado, problematizando a identificação entre o público e o estatal; e 2) uma releitura dos limites do estatuto da representação política enquanto artifício adequado para institucionalização da democracia em sociedades plurais e complexas.

Acreditamos que a articulação entre estas hipóteses nos abrirá, enquanto consequência, caminhos à perscrutação de um duplo problema. Por um lado, enquanto consequência política, nos convidará a refletir sobre os sentidos, significados, limites e possibilidades de uma proposição da democracia para além dos marcos e contornos do Estado. Por outro, enquanto consequência epistemológica, ao pôr em xeque o protagonismo do Estado no processo da constituição política da realidade, terminará por afrontar algumas das categorias através das quais a imaginação sociológica e política tradicionalmente opera em seu exercício hermenêutico de interpretação da realidade. Dedicaremos o final do texto a considerações acerca de algumas destas consequências.

\section{HIPÓTESE 1}

Propomos que um dos principais desafios postos à compreensão do repertório dos movimentos sociais contemporâneos resida na percepção de que muitas de suas práticas, valores e reivindicações transcorram sobre a superfície de um terreno inaugurado na disjunção entre Democracia e Estado. Em nosso entender, esta seria uma operação complexa e delicada, não apenas do ponto de 
vista de sua operacionalidade política, mas também e fundamentalmente, por questionar um dos principais pressupostos epistemológicos forjados pelo pensamento político moderno (TILLY \& WOOD, 2009).

A defesa do Estado como adequado codificador das pulsões políticas gestadas na sociedade constitui uma das vigas mestras de sustentação do edifício institucional político moderno. Sobrepondo a cerebrina razão pública à colérica ordem das paixões individuais e coletivas, esta proposição configura-se como ponto central das obras de pensadores gigantes como Kant e Hegel, autores que, com inigualável proeza, sintetizaram as principais chaves analíticas desenvolvidas pelo pensamento político moderno ocidental.

Em Kant, esta proposição nos é apresentada na esteira de uma cumplicidade entre os contornos da subjetividade individual e as categorias de composição do universal. Partindo das estruturas transcendentais do pensamento, Kant nos apresenta um desenho antropológico que definirá a razão do homem como dimensão contígua à sua moralidade. Propondo-nos os termos de seu imperativo categórico, nos desafia a descortinar o terreno da ação no qual a vontade individual possa se efetivar como princípio de uma legislação universal ${ }^{5}$. Com efeito, através da imediata contiguidade entre subjetividade e universalismo, Kant nos propõe, por intermédio de deduções argumentativas, o universo jurídico institucional como corolário imediato da necessidade premente ao homem de ser livre, pois, em seus termos, só é livre aquele que racionalmente sabe produzir para si a lei à qual moralmente se obrigará.

Se em Kant a fusão entre instituições jurídicas e o movimento político de composição da sociedade se efetua por intermédio de um desenho antropológico, em Hegel, este médium será a história. No centro de seu sistema filosófico, após uma longa peregrinação fenomenológica, Hegel nos propõe o Estado como o momento de (re)conhecimento absoluto do Espírito acerca de si mesmo e de sua própria verdade. Nesse sentido, o Estado para Hegel seria o enigma resolvido de toda a história política, "a ideia universal como gênero e a potência absoluta [...] o espírito que a si mesmo dá a sua realidade no progresso da história universal" (HEGEL, 1997, p. 225). Por isso, o Estado, concebido segundo o modelo da monarquia constitucional prussiana ${ }^{6}$, subsumiria todos os

5 São os termos de Kant (2007, p. 59): “Age apenas segundo uma máxima tal que possas ao mesmo tempo querer que ela se torne lei universal".

6 No $\$ 273$ dos Princípios da Filosofia do Direito, Hegel nos diz: "O aperfeiçoamento do Estado em monarquia constitucional é obra do mundo moderno e nela a ideia substancial atingiu a forma infinita. A história deste aperfeiçoamento íntimo do Espírito do mundo ou, o que é o mesmo, este desenvolvimento livre em que a Ideia liberta os seus momentos (e que não são senão momentos 
elementos constitutivamente inerentes à vida política - em especial referência a família e a sociedade civil -, sob sua égide, conciliando-os com o movimento da liberdade por ele representado.

Por essa perspectiva, o que Hegel nos diz é que, apesar de exterior à família e à sociedade civil, o Estado representaria o fim imanente a ambos. Com efeito, sobre esses sujeitos, o Estado subjetivar-se-ia, convertendo-os em momentos objetivos seus. Aqui, entendendo o Estado como a realidade em ato da liberdade concreta, Hegel o imagina enquanto momento definitivo no qual o interesse e o direito das partes se integrariam sob a égide do interesse universal. É nessa operação lógico-dedutiva que identificamos a base da fundição alquímica entre espírito/interesse/espaço público e Estado.

Analisando suas profundas distinções, seja pela via kantiana, seja pela hegeliana, podemos perceber a constituição dos vínculos ontológicos entre Estado e Sociedade - dimensão fundante do futuro Estado Democrático de Direito - como um expediente profícuo para solucionar, na articulação jurídica entre liberdade civil e igualdade jurídica, os desafios próprios à gestação de formas de sociabilidades ordeiras e disciplinadas nas democracias modernas. Estas duas matrizes do pensamento político permanecem atuais, constituindo elementos do cerne dos debates contemporâneos em teoria política, informando, em especial, a literatura de autores procedimentalistas como Habermas e Rawls.

Uma outra dimensão do problema da ordem social resolvido na identidade Estado e Sociedade, e por desdobramento, Estado e Democracia, pode ser rastreado ainda na filosofia política moderna de corte contratualista e republicanista, fundamentalmente a partir do modo como ambas recepcionam e ressignificam a noção de soberania. Esta terminologia, cuja genealogia remete às reflexões do filósofo Jean Bodin, sedimenta em seu léxico um determinado entendimento do poder político de gravitação monarquista: soberano e súdito são elementos indissociáveis e recursivos dessa concepção de poder. O soberano, ao mesmo tempo fonte e detentor do poder político, é aquele que não conhece superior na ordem externa nem inferior na ordem interna, ou seja, numa relação entre outros soberanos, é um par, e numa relação entre àqueles que devem obediência a sua soberania (seus súditos), é um hierarca, uma autoridade.

seus) como totalidades a partir dele e ao mesmo tempo os contém na unidade ideal do conceito, que é onde reside a razão real, a história desta verdadeira formação da vida moral é o objetivo da história universal" (HEGEL, 1997, p. 247). 
Ainda que a expressão lapidada no pensamento político moderno tenha se secularizado através do rechaço das fontes divinas da autoridade da realeza, ademais da invisibilização da ideia de súdito com a sua subsunção na noção de cidadania, através da conversão do demos em sujeito/portador/fonte da soberania, em termos práticos, seu exercício implicou na institucionalização deliberada de regimes estratificados em dois polos: o Estado/governo ${ }^{7}$, como representante e operador da soberania popular, de um lado, e os governados, como elementos supostamente auto-assujeitados ao seu próprio poder instituinte (PROUDHON, 1971).

Hobbes, Locke e Rousseau, cada qual a sua maneira, também foram os artífices da noção de ordem social como correspondente de uma ordem estatal. A fabulação contratualista, em suas distintas vertentes (mais ou menos populares), é parte nuclear do nosso imaginário político moderno que confere autoridade e legitimidade à representação (nas respectivas formas de governo e de Estado). Neste sentido não seria exagero lermos as linhas dos contratualistas como fonte e pavimentação do terreno por onde Kant e Hegel avançarão, assinalando tanto o lugar do indivíduo racional moderno no exercício da pactuação instituinte, quanto do movimento histórico de manifestação progressiva do Espírito da razão absoluta encarnada no Estado.

Do republicanismo herdado das releituras cívicas das experiências antigas e renascentistas, a modernidade promoveu com êxito a transmutação da ideia de bem comum e coisa pública como razão de ser do organismo político produto do pacto: 0 Estado ${ }^{8}$. Esta instituição passará assim à história como a topologia por excelência do público e suas questões. As constituições como cartas de direitos se converteram no documento base fundacional e regulador do Leviatã moderno, modulando esta convergência sui generis entre contrato social e república, entre interesses privados e virtude pública (ARAÚJO, 2004).

Mas as narrativas vitoriosas convertidas em instituições e vetores dos valores políticos hegemônicos, certamente, não eliminaram da história política as narrativas marginalizadas. Qualquer esforço genealógico de compreensão

7 Embora tratados como a mesma parte do polo em questão, não podemos perder de vista que o Estado, como estrutura jurídica institucionalizada do nomos instituída presumidamente pelo demos, é dirigido e colocado em movimento por um corpo governante transitório cujo mandato necessita, segundo a tradição democrático-liberal, de uma reiterada e temporária investidura popular. 
histórica dos debates e embates de concepções a respeito das categorias liberdade, autoridade e soberania, por exemplo, poderá atestar a riqueza do desenvolvimento dessas divergências ao longo de determinadas épocas históricas, especialmente o renascimento e o próprio iluminismo (SKINNER, 1996; 1999; POPOCK, 2003).

Do ponto de vista das tradições de esquerda, foi o anarquismo em suas expressões clássicas que pode ser considerado um continuador, em seus próprios termos, dessas concepções divergentes obliteradas. Proudhon, por exemplo, é um dos pensadores modernos que insistirá na necessidade de desestatalizar o político, especialmente através de sua crítica da noção de soberania (CUVILLIER, 1986). Mesmo a soberania popular, em sua perspectiva, nada mais é que a soberania de muitos sobre todos, quer dizer, o governo de um determinado grupo chancelado pela maioria sobre toda uma população, que passa a se assujeitar na condição (subsumida) de súdito. Ele exemplifica sua rejeição da vinculação ontológica Estado e Sociedade, produzido pelas narrativas hegemônicas (mesmo dentro da esquerda), com o seguinte raciocínio:

\begin{tabular}{|c|c|}
\hline Gênero & Espécie \\
\hline Estado & Ordem Social \\
\hline Ordem Social & Estado \\
\hline
\end{tabular}

Insistindo na necessidade de superação da visão de mundo predominante que associa ordem social e Estado, ele realiza um exercício argumentativo jogando com as categorias de gênero e espécie. Na arquitetura das narrativas predominantes que fundamentam as instituições políticas da modernidade, somente o Estado pode produzir ordem social e é capaz de regular a sociedade civil (mesmo considerando-se como produto da mesma). As espécies de vida social derivadas do Estado, este entendido como gênero, seriam apenas duas: ordem ou desordem. Proudhon nega esta concepção corrente ao operar uma inversão dessas duas topologias da política: se a ordem é a condição sine qua non de qualquer vida social (sendo assim, pois, situada como gênero), o Estado passa a configurar uma possibilidade entre outras de institucionalização das relações de poder (espécie).

Outra significante fissura aberta na filosofia política moderna pode ser cotejada na contribuição de Cornelius Castoriadis (1987), em suas reflexões 
sobre a democracia como projeto de autonomia. Partindo da tradição kantiana, ressignificada à luz das tradições socialistas e temperada por um forte viés antiautoritário e anti-hierárquico, Castoriadis retoma elementos do pensamento democrático helênico e insiste nas dimensões autoinstituintes e autorreguladoras da democracia, demarcando sua condição inescapável de horizonte e realidade política materializada no autogoverno e na autogestão.

De algum modo, podemos considerar que os movimentos sociais contemporâneos se conectam com uma tendência diagnosticada no bojo das ações coletivas dos anos 1980 e 1990, quando as teorias da sociedade civil (COHEN \& ARATO, 1994) assinalavam a centralidade das dimensões extrainstitucionais do associativismo e de um modus operandi assentado nas disputas de sentido, visões de mundo e modos de ser dos sujeitos coletivos. Esta ênfase culturalista, que foi o lastro da teoria dos novos movimentos sociais, se bem que dava conta de determinadas dinâmicas relevantes e específicas de uma nova floração de ações coletivas, operava com um certo descolamento ao buscar interpretar e analisar seus repertórios no sul global. É nesse sentido que podemos compreender a insurreição zapatista de 1994 como um caso paradigmático. Ela manifesta a conjugação, ou até mesmo, a inseparabilidade de demandas materiais e imateriais: luta por recursos, reapropriação de territórios, autonomia, reconhecimento cultural, batalhas simbólicas e disputa de visão de mundo.

O movimento zapatista, ao se territorializar através da criação dos municípios autônomos rebeldes, configurou as condições materiais para sua própria autoinstituição como fenômeno democrático não-estatal (BRANCALEONE, 2015). O que vem na sequência (não necessariamente observado em nexo causal linear), como o movimento altermundialista ("antiglobalização", segundo a mídia corporativa), as novas gerações dos movimentos indígenas, étnicos e feministas, as experiências das fábricas recuperadas na América Latina, o assembleismo popular na Argentina e em Oaxaca (México), além do reaparecimento do anarquismo como código identitário ou fonte de novos repertórios de ação e mobilizações no século XXI, nos parece uma considerável evidência de um movimento no sentido de reativação da potência constituinte do demos e esvaziamento do lugar do Estado como fundamento último e demiurgo da ordem social (ZIBECHI, 2006; IBANEZ, 2014).

É sob essa perspectiva que Holloway (2003) e Wallerstein (2005), refletindo sobre os desdobramentos da experiência zapatista, a consideram como parte de 
um processo de mudança de horizontes no qual se evidencia a possibilidade (para o segundo) ou necessidade (para o primeiro) de "mudar o mundo sem tomar o poder", pelo menos, no que se refere a reconfiguração do modo como os movimentos sociais se relacionam com o aparelho estatal.

Mais recentemente, em fenômenos como o dos Indignados, os diversos Occupies, a Primavera Árabe e as Jornadas de Junho no Brasil, todos com suas distintas especificidades, colorações e pautas mais ou menos ampliadas, confluiu de maneira muito interessante o ciberativismo e a ocupação de espaços públicos. Forma e conteúdo das ações e reivindicações estavam imersas em um forte apelo democratizante. Apontavam, de certa maneira, para a imperiosa conjugação entre democratização da política e democratização das outras esferas da vida social (AGUIAR, 2015). Nesses movimentos podemos identificar um discurso e uma prática que coloca em xeque, senão a própria ideia de representação, pelo menos o monopólio incorporado por esse instituto na constituição do político.

Outro dos pontos cardeais trazido também ao debate por estes movimentos sociais diz respeito ao questionamento de uma categoria política fortemente moderna, que definiria o 'público' como necessariamente estatal, pois fruto do avanço universalista do Estado sobre o terreno privatista da vida individual. Tomando este questionamento como objeto de nossa reflexão, encontraríamos um questionamento não apenas da perspectiva teórica forjada por pensadores como Thomas Hobbes que, ao defenderem que o representante tem a prerrogativa de criar o seu representado, apontam o Estado como agente capaz de produzir o público ao qual apelará. Mas também a algumas das premissas fundamentais que, ao longo do século $\mathrm{XX}$, sustentaram tanto os experimentos da socialdemocracia europeia, quanto também certas correntes do marxismo que visualizaria no Estado a agência central de coordenação do processo de (re)produção da ordem social.

\section{HIPÓTESE 2}

Nas demandas trazidas pelo conjunto dos movimentos sociais recentes, tem sido recorrente e constante o apelo por móveis diretos de participação na vida democrática. Tal fato nos apresenta uma problematização do estatuto da representação política enquanto artifício apto para a institucionalização dos procedimentos democráticos no interior de sociedades complexas e recortadas pelo "pluralismo das formas de vida", tal como as sociedades contemporâneas. 
Neste sentido, percebendo a instalação de um crescente antagonismo entre os anseios por participação democrática e os módulos hodiernamente ofertados pelas instituições político-representativas, arriscaremos a hipótese de que aqui se encontrariam em questão não apenas as instituições políticas em sua concretude imediata, mas sim, e talvez de forma mais radical, os meandros de uma operação conceitual que, através de uma mediação política abstrata, terminou por propor uma solução no qual os "muitos" representados poderiam estar contidos - encontrando voz e vez - em "poucos" representantes.

Para avançarmos sobre esta hipótese, propomos percorrer, brevemente, os caminhos através do qual a teoria política moderna propôs a representação como uma solução jurídico-institucional aos impasses advindos do multitudinal movimento de constituição do demos. Com efeito, através de um recorte escolhido, avançaremos nosso argumento apresentando como tanto nas linhas de Jean-Jacques Rousseau, quanto nos debates travados entre os Federalistas norte-americanos, a representação foi mobilizada, por intermédio do tema da república, como expediente para refrear os riscos emanados pelo movimento de penetração do campo popular na arena política. E confrontaremos tais leituras com a posição federalista de corte libertário, segundo a perspectiva de Proudhon.

Tomando o Contrato Social como sua obra definitiva, podemos considerar que o cerne do desafio teórico enfrentado por Rousseau foi o de viabilizar uma arquitetura do político que, estabelecendo formas de igualdade e liberdade, terminasse por colocar a lei acima dos homens ${ }^{9}$. Sob este móbile, ao propor o contrato de fundação da república nos termos da volonté générale, Rousseau nos apresenta a figura do povo enquanto sujeito político coeso que a um só tempo responde como soberano na medida em que a produz, e súdito na medida em que a obedece.

Todavia, distinguindo a vontade geral daquilo que poderia advir da somatória da vontade de todos, é importante destacar que a visada política rousseauniana se assenta não na defesa da democracia mas sim da república. Enquanto protagonista do processo de fundação e legislação da sociedade

9 Alguns anos após a publicação de O Contrato Social, Rousseau ainda se verá em torno dessa problemática. Mobilizando uma metáfora acerca de um dos mais clássicos enigmas da geometria grega (o de desenhar, no interior de um círculo perfeito, um quadrado que lhe seja idêntico na extensão de sua área), em famosa carta ao Marquês de Mirabeau, escreve dizendo sobre a dificuldade do problema teórico que enfrenta: "Eis, em minhas velhas ideias, o grande problema em política, que comparo ao da quadratura do círculo em geometria, e ao das longitudes em astronomia: encontrar uma forma de governo que ponha a lei acima dos homens" (ROUSSEAU, 2000: 119). 
política, é o demos o personagem a encarnar o espírito da absoluta soberania política. A sua participação nos assuntos cotidianos da vida política, no entanto, encontra-se relativizada, indicando-se a democracia como forma de governo mais adequada aos deuses do que aos homens. Ou seja, no paradoxo rousseauniano, por um lado, o povo se faz soberano na medida em que, participando do processo legal de constituição da ordem social, eleva a sua vontade, ou razão de ser, à categoria de vontade geral. Por outro, e justamente para manter viva a vontade geral e preservá-la da contaminação dos interesses particulares, mostra-se desejável que o povo, seja em sua inteireza ou em seu maior número, não governe, estando assim dispensado da participação efetiva na execução de sua soberania.

Percebe-se, então, que a representação, enquanto uma abstração formal, desempenha um papel fundamental no interior da arquitetura política rousseauniana. Atravessando a multidão dos homens, ela o faz povo. Recortando os vícios privados, reconfigura-os em termos de virtudes públicas. Enlaçando as vontades particulares dos muitos, sintetiza-as em vontade geral. E, assim, a partir do corte introduzido pela figura do governo, liga os homens à soberania para, concomitantemente, de sua execução os apartar. Operando em todos os níveis da obra, a representação, a um só tempo, aproxima e afasta, associa e separa, alavanca empoderamentos e demarca campos de sujeição. Propondo a república enquanto princípio de constituição do político e a democracia enquanto uma forma - entre outras - de gestão governamental, pelo crivo representativo, Rousseau articula essas duas dimensões em uma estrutura que ao tempo em que garante pequenas doses de governo popular, também se alinha em proteger o político dos perigos potencialmente circunscritos pela "democracia absoluta".

Por encampar o tema da república ao invés do da democracia - em grande medida tomando-os como dimensões antagônicas - o foco rousseauniano incidirá mais nas formas através das quais as diversas forças que operam no jogo de constituição do real se neutralizam do que na exploração das possibilidades que essas forças encontrariam para entre si comporem-se. Por essa razão, o tema central em Rousseau será o da unidade e não o do pluralismo. Ao propor a figura do povo enquanto encarnação da vontade geral, Rousseau é categórico em afirmar que sua soberania só se mantém ao preço de sua unificação. Assim, o processo no qual um povo se faz um povo pressupõe perspectivas unidimensionais e falas em uníssono. A diferença é inimiga do povo, pois afeta a estabilidade formal. Se por meio de uma abstração 
transcendental o povo se inaugura como personagem a representar a dimensão multitudinal dos homens de outrora, ele somente o faz ao decantar a pluralidade, para ressignificá-la em unidade. Destarte, se o povo é a ideia que soluciona transcendental e representativamente a multidão de homens, por seu turno, a figura polimórfica da multidão é a presença que eterna e imanentemente perturbará a coesão monomórfica do corpo político soberano. Mais uma vez, enquanto invenção frágil da humanidade coletiva, o político dialogará em suas bordas com a crise. De tal forma que não nos parece exagero identificarmos que, apesar das insistências rousseaunianas em sentido contrário, a noção de soberania carregaria em si um forte traço de representação, pois, distinta da vontade de todos - signo da expressão plural da sociedade - a vontade geral, ao se definir enquanto uma síntese transcendental, se ligaria à primeira, mas também dela se distinguiria. Com efeito, através do mecanismo da representação, a imaginação rousseauniana encontra seu paradoxo maior ao submeter a efetivação do governo de todos aos marcos políticos, jurídicos e simbólicos do governo de um só.

Se as linhas rousseaunianas nos fornecem bases epistemológicas para a afirmação da representação como campo de neutralização das forças plurais que constituem o corpo do demos, os debates entre os federalistas norteamericanos nos revelam o testemunho histórico privilegiado acerca desta operação.

Composto por uma série de artigos que pautariam importantes reformas nas instituições políticas norte-americanas, chamamos atenção nos debates entre os federalistas para a atualização da distinção entre república e democracia. Tomando-se como referência a revolta de camponeses pobres e endividados de Massachusetts, que, sob o comando de Daniel Shays, rebelaramse contra a prisão de devedores e a espoliação de suas terras, os textos dos federalistas são repletos da necessidade de uma constituição política enérgica e liberal capaz de livrar o país dos riscos da "anarquia e do caos", derrocando-se assim as pretensões à "democracia perfeita" e a "liberdade absoluta" reivindicada pelo "povo miúdo", em nome de um "poder executivo". Impunhase, assim, a necessidade de procedimentos políticos capazes não de agradar o país, mas sim de salvá-lo ${ }^{10}$.

10 Sob este Espírito, Domenico Losurdo capta provocativamente a promulgação da nova constituição norte-americana como um genuíno golpe de Estado: "Isto é: a virada político-constitucional não estava legitimada nem pela ordem jurídica existente nem pelo apelo à soberania popular, mas pela absoluta necessidade de poupar ao país os ataques à propriedade, o caos e a anarquia que sobre ele pendiam ameaçadoramente" (LOSURDO, 2004: 98). 
Desta forma, lendo a democracia pela chave do tumulto, os federalistas proporão a república - e por seu intermédio, a representação - como uma forma de afastar os riscos políticos apresentados pelo "populacho" e gerar possibilidade de controle acerca das ações conflitivas decorrentes das facções, protegendo, assim, o Estado da "guerra e das revoluções", os "dois males mortais da sociedade":

Na América The Federalist se apressa em esclarecer que a república se diferencia das democracias (as quais sempre ofereceram um espetáculo de turbulência e de conflitos) pelo fato de que a primeira, baseada no sistema de representação, consiste na delegação da ação governativa a um pequeno número de cidadãos eleitos pelos outros, também neste caso com a exclusão substancial de qualquer capacidade de iniciativa popular autônoma; a fase preparatória e os trabalhos da convenção da Filadélfia são dominados pela preocupação sempre em relação à rebelião verificada em Massachusetts, de terminar com a anarquia, com os excessos da democracia e com a agitação dos demagogos ou pretensos patriotas. (LOSURDO, 2004, p. 101)

Como se pode observar, seja com a sutileza de Rousseau, seja na fórmula explícita dos federalistas estadunidenses, a aversão à anarquia da multidão, o medo do populacho e o receio da contaminação do espaço público pela gente miúda, modalidades não tão distintas daquilo que Thaís Aguiar (2015) interpretou como presença inconteste da demofobia no pensamento político moderno, são expressivas evidências de alguns elementos que modularam as fundações normativas e institucionais da representação política tal como a herdamos. Para além do debate demográfico-territorial (quantitativo) e moral (qualitativo) consagrado por Benjamin Constant com a sua liberdade dos antigos e dos modernos, se trata de compreender a complexa operação que viabilizou a conversão do governo dos proprietários sobre os não proprietários em governo do povo sobre si mesmo. A fabulosa prestidigitação epistemológica e institucional que permitiu a fusão entre soberania e povo, entre Estado e Democracia.

Para isso retomaremos novamente Proudhon, dando continuidade à sua crítica da soberania e da autoridade como princípio do governo do homem sobre o homem, culminando no modo como o mesmo lapidará uma concepção de federalismo em chave libertária. Em outros termos: reabilitando a anarquia da multidão como princípio de fundação do autogoverno e da unidade na pluralidade (BOUGLÉ, 2014).

Se nos parece correto perceber que a noção de autoridade em Proudhon 
varia em obras relativamente distantes em sua atividade política e intelectual, como "O que é a propriedade?" (1971 [1840]) e em "Do princípio federativo" (1996 [1863]), o cerne do argumento que irá lastrear tanto a ideia de anarquia quanto a ulterior de democracia industrial será aquela de pulverizar, descentrar e disseminar as estruturas de poder da sociedade moderna no maior número de organismos possíveis, a ponto de garantir "o governo de cada um por cada um". Crítico feroz de todos os monopólios, econômicos ou políticos, deposita na potência associativa da massa de trabalhadores a capacidade de estabelecimento de vínculos e laços em uma dupla dimensão: de trabalho, produção e consumo por um lado, e territoriais por outro, para atender as mais diversas necessidades humanas. Ao primeiro tipo de pacto de associação Proudhon nomeava mutualismo, à luz da experiência operária do século XIX. Ao segundo tipo, federalismo.

Considerando a gramática política e filosófica da França novecentista, Proudhon concebe a vinculação prática das esferas morais de independência e solidariedade (individual e coletiva) por meio da ideia de contrato. Inimigo de Rousseau, nosso autor não deixa de ser um contratualista, embora entendendo o contrato não como fábula ou mito fundador da associação política, mas como projeto a ser efetivamente implementado por homens livres.

O contrato político não adquire toda a sua dignidade e moralidade senão com a condição 1) de ser sinalagmático e comutativo; 2) de estar contido, quanto ao seu objeto, dentro de certos limites: duas condições que se supõe existirem no regime democrático, mas que, ainda aí, não são quase senão uma ficção. Pode-se dizer que numa democracia representativa e centralizadora, numa monarquia constitucional e censorial, numa república comunista, à maneira de Platão, o contrato político que liga o cidadão ao Estado seja igual e recíproco? Pode dizerse que esse contrato, que tira aos cidadãos metade ou dois terços da sua soberania e o quarto do seu produto, esteja encerrado nos seus justos limites? Seria mais verdade dizer, o que a experiência confirma demasiadas vezes, que o contrato, em todos esses sistemas, é exorbitante, oneroso, pois que ele é, para uma parte mais ou menos considerável, sem compensação; e aleatório, pois que a vantagem prometida, à partida insuficiente, nem sequer é assegurada. (PROUDHON, 1996, p. 65)

Dessa maneira Proudhon será um dos primeiros autores no campo do socialismo a divisar uma proposta de associação política edificada de baixo para cima, sob o protagonismo dos trabalhadores, entendidos na sua condição elementar de produtores - com a abolição do salariado (quer dizer, do próprio mercado de trabalho como circuito de mercantilização do trabalho). 
Certamente, o núcleo elementar dessa associação será constituído pelas comunas, territórios conhecidos como municípios, espaços capazes de viabilizar o funcionamento de assembleias, conselhos e outros arranjos de democracia direta. No interior (e mesmo pra além) da comuna, se associam de forma mutualista, organismos de produção, trabalho, crédito e consumo. Entre comunas, os laços que se estabelecem para ampliar o espectro de circulação territorial dos seus membros conforma a federação. Os pontos de coordenação e execução das deliberações oriundas de cada unidade que compõe a comuna e a federação, juntamente com as próprias unidades (associações) que conformam o corpo político, constituem os órgãos de autoadministração da federação. A diferença com a matéria que funda o instituto da representação dos modernos, é que estes organismos e pontos de coordenação não podem exercer o monopólio da legislação e regulação da vida social como espaços autonomizados do político. Ambos pertencem às dinâmicas sociais coletivas e devem às suas respectivas partes instituintes responsabilidade e obediência nos termos dos mandatos imperativos. Por isso a forma política da anarquia, do governo de cada um por cada um, da unidade na pluralidade, é o federalismo. Sua condição material é o trabalho associado e o autogoverno dos produtores.

Nesse sentido, o lugar da democracia na leitura proudhoniana é muito peculiar. Entendida menos como um regime de governo, e mais como um processo contínuo de disseminação da igualdade e da liberdade nos seguintes termos: cabe àqueles que serão afetados por todo ato deliberativo o legítimo direito de ter parte em tal processo de decisão. Portanto as correspondências entre democratização, autonomia e anarquia.

Os movimentos sociais contemporâneos que sublinhamos atuam sobre marcos de reabilitação da democracia direta: seja via grupos de afinidade dispersos mas vinculados por laços de solidariedade que os tornam capazes de grandes ações espetaculares seguida de dispersão; seja via territorialização de experimentos instituintes de autogovernos.

Se tomarmos em consideração um dos eixos centrais de configuração das Jornadas brasileiras de Junho de 2013, encontraremos uma problematização direta e aguda acerca dos limites dos estatutos da representação. Em meio a explosão de demandas apresentadas durante o ciclo de protestos e materializadas através de um amplo e diverso mar de cartazes e palavras de ordem, um mote se destacou pelo poder de produção de vínculos e concordâncias entre os múltiplos atores que ali estavam: o mote da não representação. Contrariando a sanha de partidos e movimentos tradicionais que 
procuravam, se não conduzir, ao menos pautar a energia das ruas, o brado do "Não me representa" abria caminhos e linhas de fuga através dos quais a multidão ali presente procurava tanto retomar para si a própria verve catalizadora da indignação, quanto indicar que os múltiplos desejos e anseios que atravessam a vida social não se encerram nos códigos de captura mobilizados pelas instituições representativas. Este aspecto nos parece importante para contextualizarmos nossa discussão e pensarmos dois momentos que condicionaram os destinos experimentados pelas Jornadas de Junho de 2013.

Por um lado, lendo a não representação como linguagem galvanizadora da indignação circulante nas ruas, os poderes institucionalmente estabelecidos recusaram-se a responder substantiva e propositivamente as demandas ali apresentadas. Inicialmente, ao não se deixarem atravessar pela potência emanada pelo movimento, assimilando em chave crítica e renovadora o seu recado, optaram pelo fechamento ao diálogo, pela desconfiança, pela criminalização e pela consequente repressão ${ }^{11}$.

Por outro lado, 2013 nos revelou que a crítica à institucionalidade não representa a crítica à organização. Longe disto, enquanto movimento de renovação societária, as Jornadas serviram de palco para a floração e enunciação de um sem número de coletivos políticos e culturais que tem atuado em torno de pautas que variam dos direitos humanos ao direito à cidade, das lutas feministas à ecologia, passando pela reaglutinação de frentes políticas libertárias, anarquistas e comunistas (BRANCALEONE \& DE BEM, 2014).

Pensando ainda sobre o repertório dos movimentos sociais contemporâneos a partir da chave que interliga a crítica da representação à renovação de circuitos acionais diretos engendrados por atuações desde abajo, parece-nos interessante destacarmos a ênfase dada ao tema da horizontalidade e da ação direta. Mobilizando a horizontalidade como uma espécie de utopia prática, este aspecto tem recortado os novos movimentos e coletivos desde suas estruturas organizativas até seus expedientes de tomada de decisão. Entre outros aspectos, este elemento tem se mostrado decisivo na composição de suas

11 Inclusive, podemos debitar na conta da esquerda institucionalizada parcela substantiva da responsabilidade dos desdobramentos do pós-2013 ao não dar vazão política às demandas democratizantes e socializantes presentes nas ruas. Desse modo, se permitiu que setores conservadores organizados, especialmente aqueles alinhados com o oligopólio midiático e empresarial, pudessem exercer a captura midiática seletiva do conteúdo dos protestos, remodelando as evidentes insatisfações populares em narrativas antipetistas para operar o golpe de Estado em 2016. 
atuações públicas. Através do investimento na horizontalidade, observamos uma tendência dos movimentos em descartarem o tradicional modelo "orador de tribuna" - que confere hipervalorização a certos perfis de lideranças - em nome de uma morfologia que termina por conferir maior protagonismo às bases e à própria performance do corpo coletivo em ato. Este deslocamento tem marcado, como traço fundamental, um relevante investimento deste conjunto de movimentos em mecanismos internos de democratização radical que retroalimenta protagonismos muito bem expressos nas práticas de ação direta, como pode ser observado mesmo superficialmente tanto nas experiências dos ocuppies e dos indignados, quanto nas dimensões performativas de atuação, em escala global, das slutwalks aos black blocs.

Assim, ao arriscarmos esta hipótese, gostaríamos de indicar que, em referência a estes movimentos sociais contemporâneos, algo de substantivo germina no interior de nossa vida social, apontando a saturação dos mecanismos de responsividade ofertados pelas instituições que operam o jogo da representação política. Este não é um dado de pouca relevância. Longe disto, caracteriza um dos principais nós górdios que desafia o aprofundamento (ou realização efetiva) da experiência democrática. Não enfrentá-lo é fornecer terreno ao avanço das panaceias conservadoras e reacionárias que disseminam modalidades de antipolítica que alimentam o autoritarismo, a apatia, a xenofobia e a desconsideração do outro e de tudo aquilo que represente a frutificação da diversidade. Ao longo dos últimos séculos, não foram poucas as vozes que ensinaram que os problemas democráticos se resolvem com mais democracia (ou processos democratizantes) e não com menos. Através deste ensaio, procuramos nos somar a estas vozes.

Se ao longo de sua breve história, a sociologia procurou fiar a legitimidade de seu discurso público na conexão entre suas intuições reflexivas e os dilemas concretos que atravessam e compõe a estruturação da realidade, o presente cenário incita à renovação dos velhos recursos simbólicos presentes na moderna tradição sociológica e política (LEVINE, 1997). Se até aqui avançamos depositando fichas na capacidade do Estado em produzir e guiar a democracia, talvez tenha chegado o momento de repensarmos nossas categorias e franquear diálogo com outras narrativas intelectuais e políticas. As ruas falam. Cabe-nos ouvi-las. 


\section{CONSIDERAÇÕES FINAIS: A DEMOCRACIA CONTRA E ALÉM DO ESTADO}

A emergência do moderno Estado-Nação não pode ser compreendida sem considerar o entrelaçamento de complexos processos sociais, econômicos, políticos e culturais que resultaram na constituição daquilo que Wallerstein (2005) vem denominando como sistema-mundo moderno, oriundo da convergência entre o fenômeno da colonização do continente americano com a abertura do circuito mercantil do Atlântico Norte pela Europa no século XV; dos desdobramentos da Revolução Francesa no século XVIII na configuração do imaginário político de corte liberal e republicano e suas correspondentes engenharias institucionais; e dos efeitos da Revolução Industrial no século XIX, com seus imperativos técnicos e demográficos para a constituição de um sistema de produção, circulação e consumo de base nacional e internacional. Tal concepção implica no entendimento da formação e consolidação de um sistema interestatal responsável por organizar e representar a relativa autonomia e independência de determinados povos e territórios em relação a outros povos e territórios, na condição de organismos políticos reciprocamente reconhecidos (BRAUDEL, 1997).

Se na teoria política as principais narrativas modernas responsáveis pela legitimação da existência do Estado provinham do campo filosófico jusnaturalista através do chamado contratualismo, em suas diversas variantes, que afirmava o caráter ontológico da conjugação aritmética das vontades individuais racionais e autônomas como o substrato da existência da soberania estatal, do ponto de vista histórico os eventos e processos que culminaram na formação dos diversos Estados Nacionais estão inegavelmente relacionados a atos de conquista militar, adaptação inter e intra-oligárquica, alianças e reconfiguração de casas aristocráticas, espoliação econômica, enfim, se explicam mais pelo domínio da usurpação e da violência do que pelo domínio da livre deliberação (ELIAS, 1994; LEVAL, 1978; BAKUNIN, 2011).

A difícil, controversa e delicada aproximação entre Estado e Democracia pode ser observada de modo mais delineado considerando pelo menos dois grandes momentos históricos. De um lado, o experimento de colonização puritana do território que ficaria conhecido como Estados Unidos da América (incluindo seus diversos matizes radicais libertários e socialistos), encarnado nas figuras de seus pioneiros que destilaram (sob a jugular dos povos indígenas, cabe mencionar) um virtuoso e rico caldo de associativismo que cimentou 
nessa etapa heroica e fundacional a base da liberdade federativa das townships, bem como sua correlata concepção de autogoverno (TOCQUEVILLE, 1988; 2005).

De outro lado temos a contribuição do movimento operário, na condição de resistência ativa, que culminou na constituição de um sujeito político coletivo capaz de ameaçar a ordem social estatal capitalista em fase de consolidação. Nesse sentido, a emergência do Trabalho como questão social provocou nos operadores sociais do Estado e do Capital uma reação inicialmente negativa (repressão) mas posteriormente positiva (incorporação e adaptação), esta última, essencial para produzir o arrefecimento do antagonismo representado pelo Trabalho, tornando-o um polo dinâmico do próprio processo de desenvolvimento social e econômico das sociedades estatais-mercantis nacionais. Isso implicava na abertura de canais de colaboração para a incorporação de setores da classe trabalhadora na gestão do aparato estatal (no qual o movimento sufragista será entendido, e defendido, na perspectiva do processo de democratização do Estado), bem como no incremento do processo de reprodução da força de trabalho através da regulação da exploração e da ampliação das faixas sociais de consumo. Tal movimento de reação positiva, intencionalmente ou não, teria ido ao encontro da "aposta civilizatória" realizada por setores socialistas e trabalhistas do movimento operário, que por sua vez se fortaleceram através da legitimação do sufrágio eleitoral e do reconhecimento legal dos sindicatos como mediadores e representantes exclusivos dos trabalhadores durante os litígios com a patronal.

O Estado moderno, figurando como a coroação do processo de autonomização do político no âmbito do sistema-mundo moderno, significou sua progressiva naturalização como campo dotado de regras e dinâmicas específicas, autorizando o entendimento de sua manifestação como um resultado sine qua non do desenvolvimento da divisão social do trabalho. A expertise política e a profissionalização dos operadores e agentes estatais, por sua vez, foram a condição necessária para a complexa tarefa de condução do gigantesco e centralizado aparato monopolizador da produção legislativa, da aplicação da justiça e do uso legítimo da violência.

O contraponto aceitável e assimilável à constituição da ordem estatal moderna, tendo em vista o papel jogado pelo municipalismo e associativismo puritano ianque de um lado, e o movimento operário de outro, foi a possibilidade de articular dinâmicas de descentralização ou a divisão de competências administrativas e legislativas à luz das formulações federalistas 
liberais, e a ampliação do sufrágio e da elegibilidade para cargos e postos estatais ao conjunto das populações naturais à circunscrição territorial nacional. Tudo isso, obviamente, calcado na regulação da relação entre governantes e governados por princípios ou cartas constitucionais. A isso se atribui o entendimento mais consensuado do Estado de Direito. Também é necessário mencionar que as manifestações particulares dos Estados de Direito modernos, ainda que estruturadas sob estas bases, assumiram feições próprias em resposta às condições sociais e históricas de cada caso.

O estatuto democrático do Estado de Direito, portanto, diz respeito a determinados critérios ou garantias que regulam a relação governo governado. Tal regulação, no entanto, não impede a ascendência política, econômica, social, etc, dos governos em relação aos governados, tanto para favorecer a reprodução de determinados grupos sociais na condição de "classe política ou gestora", quando na capacidade de direcionar ou induzir determinadas dinâmicas do corpo social como um todo - o que significa de fato governar a sociedade. A dimensão democrática dos Estados, nessa perspectiva, é menos uma condição inerente da esfera pública (republicanamente entendida), do que um movimento incessante de democratização que responde como contrapeso aos riscos de incomunicabilidade entre Estado e Sociedade, já que a realização plena do movimento de democratização implicaria na dissolução de muitos aspectos e elementos centrais para a atual configuração do próprio Estado.

Paradoxalmente, as experiências históricas das polis gregas ou das comunas italianas renascentistas integram o núcleo do nosso imaginário político democrático moderno. Ora, sua condição democrática se assenta justamente na não estatalidade de suas instituições: são democracias não-estatais. Para além da antinomia supostamente insuperável lançada por Benjamin Constant sobre a liberdade dos antigos e a dos modernos, o ponto é que o horizonte da cidadania moderna é a Cidade, o território local, do município, e isso não quer dizer outra coisa que capacidade de autodeterminação, autoinstituição e autocriação coletiva. Isso significa, pois, autonomia e autogoverno (CASTORIADIS, 1986). Ora, a articulação imprescindível entre as diversas coletividades autogovernadas demandaria instâncias de coordenação da cooperação social, que são justamente parte das funções que o Estado moderno usurpou e tomou para si (KROPOTKIN, 2012). Este é o dark side of the moon da teoria política moderna. Os desdobramentos consequentes do "enigma resolvido de todas as constituições”. Este é o terreno do federalismo libertário ou anarquista. 
Curiosamente foi Tocqueville um dos primeiros teóricos a buscar uma compreensão da democracia para além da moderna vulgata de regime político. Ao analisar (e testemunhar) detidamente o que para ele era entendido como a pujança do tecido comunitário e associativo dos cidadãos estadunidenses durante o período épico de construção da nova nação, o aristocrata francês cunhou uma concepção de democracia como processo social de longo prazo e imprevisível devir, implicado nas dinâmicas e desdobramentos do igualitarismo social como elemento motor do mundo moderno. Em sociedades não estamentais a mobilidade social é um dos pilares do ordenamento das instituições e das interações sociais. Como implicações de várias ordens estão incluídas a instabilidade moral e o enfraquecimento das tradições, a disseminação de mudanças dentro e fora das instituições, a radicalização dos processos de individualização e, o que era trágico para o nosso autor, coerente com a sua condição aristocrática, a universalização do homem comum e mediano (o "reinado dos homens medíocres").

Os movimentos sociais forjados ao longo dos três últimos séculos, como fenômenos de ação coletiva racionalmente orientada para determinados fins (não necessariamente racionais), se inserem no âmbito do desenvolvimento processual da democracia. São fenômenos de democratização em grande medida, e não apenas por desafiar o Estado e as estruturas econômicas e morais vigentes, na condição de contrapesos democratizadores, mas fundamentalmente por existirem como lugares e espaços de afirmação da democracia que não existe (e nem poderia existir) no Estado. É verdade que a literatura que busca enfatizar essa dimensão prefigurativa dos movimentos sociais é uma literatura relativamente recente, considerando a visão mais convencionalizada que buscava interpretar os movimentos sociais como "guardiões" de uma suposta condição democrática dos Estados: a então sociedade civil a quem os governantes precisam prestar contas.

A título de exemplo, podemos mencionar a chave de leitura teórica construída pelo Coletivo ACySE - CLACSO (2012) para compreender estas não tão novas dinâmicas de auto-organização oriundas do mundo popular e subalterno (e não restritas a ele), lançando mão do conceito de sociabilidades emergentes: arranjos interativos, práticas e representações da ordem social guiados pelo móbile da horizontalidade, do apoio mútuo, do livre acordo, da participação protagonista, da criatividade social, da apropriação do valor de uso, da ação direta, da autonomia individual e coletiva, entre outros elementos (COLETIVO ACySE, 2012). Tais características, notadamente mais visíveis nos 
movimentos e lutas sociais das últimas duas décadas, e cujo marco de referência em grande medida é o movimento zapatista, nos permitem esboçar a compreensão da emergência de uma nova cultura política que se realiza, intencionalmente ou não, a partir da constituição de espaços e circuitos autônomos, auto-organizados e democráticos. Eis um dos cernes dos tensionamentos com os imperativos da representação.

Aliás, a noção de autonomia é a melhor forma de expressar esse novo tempo do mundo que atravessa o universo dos subalternos. Para além da crítica da inevitável cegueira corporativa dos movimentos sociais por parte daqueles que reivindicam o Estado como o público por excelência, e portanto, como a encarnação do universalismo contra a fragmentação dos particularismos da sociedade civil, cabe mencionar que o substrato sob o qual se constituem esses espaços e circuitos de autonomia é justamente aquele dos tecidos comunitários colaborativos, das redes de solidariedade e dos laços de cooperação, ou aquilo que os antropólogos se referem como "economia de reciprocidade" para aludir às sociedades não estatais-mercantis (CAILLE, 2002; MAUSS, 2003). Ao que parece, há um processo de construção, estímulo ou mesmo redescoberta, de uma ética pluriversalista em curso.

Ao questionar os limites do Estado enquanto representante (único) ou salvaguarda da democracia, muitas das bandeiras trazidas ao debate político pelos movimentos sociais contemporâneos vêm se articulando em torno defesa da democracia como modo de vida para além dos marcos estritos de definição do próprio Estado Democrático de Direito. Tentando problematizar a ideia de que este possa a ser um codificador insuficiente para as demandas originadas naquela, estaria aqui colocada em xeque uma longa tradição do pensamento político e jurídico moderno que, iniciada em pensadores como Imannuel Kant e Georg Hegel desaguaria, atualmente, em autores como Jürgen Habermas e John Rawls. Talvez fosse o caso de revisitar outras tradições obliteradas pela teoria política tradicional, cimentadas pelo consenso liberal e marxista, como aquelas nas quais figuram personagens como Charles Fourier, Joseph-Pierre Proudhon e Mikhail Bakunin, mas sem jamais perder de vista a necessidade de diálogo honesto e descolonizador com as emergentes filosofias indígenas e africanas que afortunamente vem ganhando espaço no debate político latinoamericano (DUSSEL, MENDIETA \& BOHORQUEZ, 2010). Embora não tenha sido objetivo desse modesto texto, por razões de espaço e limitações de formação intelectual dos autores, também compartilhamos muitas das preocupações éticas e teóricas que reiteram o desejo e disposição em abrir os diques do 
represamento epistemológico para dar vazão ao movimento que podemos encontrar hoje em curso em boa parte do mundo subalterno, colonizado e periférico na voz dos chamados "intelectuais nativos" (no sentido amplo dos dois termos), endossando, na trilha sonora multicromática do chamado perspectivismo antropológico (VIVEIROS DE CASTRO, 2002), o movimento de indianização do pensamento político contemporâneo, redefinindo as condições de possibilidade para a afirmação de formas de vida democráticas ancoradas em marcos outros que não os exclusivos da forma Estado e da forma Capital.

\section{REFERÊNCIAS}

ABENSOUR, Miguel. A democracia contra o Estado. Belo Horizonte: Ed.UFMG, 1998.

ARAUJO, Cícero Romão. Quod Omnes Tangit: fundações da república e do Estado. Tese (Livre-Docência em Teoria Política). Departamento de Ciência Política - Faculdade de Filosofia, Letras e Ciências Humanas. Universidade de São Paulo. São Paulo, 2004.

BAKUNIN, Mikahil. Deus e o Estado. São Paulo: Hedra, 2011.

A essência da religião: o patriotismo. São Paulo: Imaginário, 2009. . Escritos de filosofia política I. Madrid: Alianza Editorial, 1978.

Estatismo e anarquia. São Paulo: Imaginário, 2003.

BOUGLE, Celestin. A sociologia de Proudhon. São Paulo: Imaginário, 2014.

BUBER, Martin. Caminos de utopia. Mexico: Fondo de Cultura Economica, 1955.

BRANCALEONE, Cassio. Teoria social, democracia e autonomia. Uma interpretação da experiência zapatista de autogoverno. Rio de Janeiro: Azougue, 2015.

BRANCALEONE, Cassio \& DE BEM, Daniel. As rebeliões da tarifa e as Jornadas de Junho no Brasil. Porto Alegre: Deriva, 2014.

BRAUDEL, Fernand. Civilização material, economia e capitalismo: séculos XV-XVIII. v 1. São Paulo: Martins Fontes, 1997. 
CAILLÉ, Alain. Antropologia do dom. O terceiro paradigma. Rio de Janeiro: Vozes, 2002.

CASTORIADIS, Cornelius. A instituição imaginária da sociedade. $3^{a}$ ed. Rio de Janeiro: Paz e Terra, 1986.

"A polis grega e a criação da democracia". Em: As encruzilhadas do labirinto 2: os domínios do homem. São Paulo: Paz e Terra, 1987.

COHEN, Jean \& ARATO, Andrew. Civil society and political theory. Cambridge/Massachusetts/London: MIT Press, 1994.

COLECTIVO SITUACIONES (comp). Contrapoder: una introducción. Buenos Aires: Mano en mano, 2001.

COLETIVO ACySE. "Anticapitalismos y sociabilidades emergentes: nociones en contrucción”. Em: BRANCALEONE, Cassio e CHAGUACEDA, Armando (org). Mobilizaciones sociales y sociabilidades emergentes en America Latina. Buenos Aires: CLACSO, 2012.

CUVILliER, Armand (org). Proudhon. 2a ed. México: Fondo de Cultura Económica, 1986.

DUSSEL, Enrique; MENDIETA, Eduardo; BOHORQUEZ, Carmen. El pensamiento filosofico latinoamericano, del Caribe y "latino" (1300-2000). México: Siglo XXI/CREFAL, 2010.

ELIAS, Norbert. O processo civilizador. Rio de Janeiro: Zahar, 1994. 2 v.

GAUCHET, Marcel. A democracia contra ela mesma. São Paulo: Editora Radical Livros, 2009.

FOURIER, Charles. El falansterio. Buenos Aires: Ediciones Godot, 2008.

HEGEL, Friedrich. Princípios da filosofia do direito. São Paulo: Martins Fontes, 1997.

HELLER, Agnes. La revolución de la vida cotidiana. Barcelona: Península, 1982.

HOLLOWAY, John. Crack capitalism. London: Pluto Press, 2010.

Mudar o mundo sem tomar o poder. São Paulo: Viramundo, 2003. 
HOLLOWAY, John; PELAEZ, Eloína (ed). Zapatista! London: Pluto Press 1998.

IBANEZ, Tomás. Anarquismo en movimiento. Buenos Aires: Libros de Anarres, 2014.

KANT, Immanuel. Fundamentação da metafísica dos costumes. Lisboa: Edições 70, 2007.

KROPOTKIN, Piort. O Apoio Mútuo. Um fator de evolução. Porto Alegre/São Sebastião: Deriva/A Senhora Editora, 2012.

LA BOETIE, Etienne. Discurso sobre a servidão voluntária. São Paulo: Editora Revista dos Tribunais, 2003.

LEVAL, Gaston. El Estado en la história. Madrid: Ed. Zero, 1978.

LEVINE, Donald. Visões da tradição sociológica. Rio de Janeiro: Zahar, 1997.

LOSURDO, Domenico. Democracia ou bonapartismo: triunfo e decadência do sufrágio universal. Rio de Janeiro: Editora UFRJ, 2004.

MAUSS, Marcel. "Ensaio sobre a dádiva”. In: Sociologia e antropologia. São Paulo: Cosac Naify, 2003.

MELLO, Rodrigo. "Conflito, Instituições e Liberdade em Maquiavel”. CSOnline - Revista Eletrônica de Ciências Sociais, Juiz de Fora, Ano 8, Ed. 19, Jan./Jun., 2015 .

MICHELS, Robert. A Sociologia dos Partidos Políticos. Brasília: UnB, 1982.

MOORE JR, Barrington. As origens sociais da ditadura e da democracia: senhores e camponeses na construção do mundo moderno. Lisboa: Edições Cosmos; Santos: Martins Fontes, 1967.

MORIN, Edgar. O problema epistemológico da complexidade. Lisboa: Publicações Europa-América, 1996.

NEGRI, Antonio. O Poder Constituinte: Ensaios sobre as alternativas da modernidade. Rio de Janeiro: DP\&A Editora, 2002.

NEGRI, Antonio; HARDT, Michael. O trabalho de Dionísio: para uma crítica ao Estado pós-moderno. Juiz de Fora: Pazulin/EDUFJF, 2004.

PROUDHON, Pierre-Joseph. O que é a propriedade?. Lisboa: Estampa, 1971. 
Do princípio federativo e da necessidade de reconstruir o partido da revolução. Lisboa: Colibri, 1996.

POCOCK, J. Linguagens do ideário político. São Paulo: EDUSP, 2003.

QUIJANO, Anibal. "Colonialidade do poder e classificação social". In: SANTOS, Boaventura; MENESES, Maria. Epistemologias do sul. São Paulo: Cortez, 2010.

RANCIERE, Jacques. O ódio à democracia. São Paulo: Boitempo, 2014.

ROUSSEAU, Jean Jacques. Carta ao marquês de Mirabeau. Cadernos de Ética e Filosofia Política, São Paulo, v. 2, p. 117-122, 2000.

SOUSA SANTOS, Boaventura (org). Democratizar a democracia. Rio de Janeiro: Civilização Brasileira, 2002.

SCOTT, James. Los dominados y el arte de la resistencia. México: Era, 2000. The art of not being governed. London: Yale University, 2009.

SKINNER, Quentin. As fundações do pensamento político moderno. São Paulo: Cia das Letras, 1996.

. Liberdade antes do liberalismo. São Paulo: Ed.Unesp, 1999.

TILLY, Charles; WOOD, Lesley. Social Movements: 1768-2008. Boulder: Paradigm Publishers, 2009.

TOCQUEVILLE, Alexis. Igualdade social e liberdade política. São Paulo: Nerman, 1988.

A democracia na América. Vols 1 e 2. São Paulo: Martins Fontes, 2005.

WALLERSTEIN, Immanuel. Análisis de sistemas-mundo: una introducción. México: Siglo XXI, 2005.

VIVEIROS DE CASTRO, Eduardo. A Inconstância da Alma Selvagem. São Paulo: Cosac \& Naify, 2002.

ZIBECHI, Raul. Dispersar el poder. Los movimientos sociales como poderes no estatales. Buenos Aires: Tinta Limón, 2006. 


\section{Movimientos sociales contemporáneos y democracia más allá del estado: algunas hipóteses para el debate}

Resumen: A lo largo de las últimas décadas, los Estados de intención democrática vienen experimentando un reto de gran magnitud que tiene, en las banderas levantadas por un nuevo conjunto de movimientos sociales, su más notable síntoma: en especial, la crisis del estatuto de la representación política. Esta crisis estaría afectando, de modo radical, los nexos de vinculación entre las instituciones del Estado y el resto de la vida social, y, en el límite, podría condenar la legitimidad del diseño que actualmente configura a los dispositivos de inspiración democrática de las poliarquías contemporáneas. En este artículo presentamos dos hipótesis para pensar la crisis de la representación ante las interfaces entre movimientos sociales y democracia. Además, anclando nuestras reflexiones en el actual circuito de la indignación global, nos proponemos identificar los significados y consecuencias de un doble problema: por un lado, las condiciones de posibilidad de constitución de un horizonte democrático erigido más allá de las fronteras normativas e institucionales de la forma-Estado y de la forma-Capital, y de otro, el sentido de algunos obstáculos epistemológicos que centrales en la imaginación sociológica y política moderna, prisionera del estadocentrismo como principio ontológico de construcción del orden social.

Palabras-clave: Representación. Estado. Democracia. Movimientos Sociales. 